TITLE:

Pagurus imafukui, a New Species of Deep-water Hermit Crab (Crustacea : Anomura: Paguridae), with Notes on its Larvas

$\operatorname{AUTHOR}(S)$ :

Mclaughlin, Patsy A.; Konishi, Kooichi

CITATION:

Mclaughlin, Patsy A....[et al]. Pagurus imafukui, a New Species of Deep-water Hermit Crab (Crustacea: Anomura: Paguridae), with Notes on its Larvas. PUBLICATIONS OF THE SETO MARINE BIOLOGICAL LABORATORY 1994, 36(4): 211-222

ISSUE DATE:

1994-11-15

URL:

http://hdl.handle.net/2433/176238

RIGHT: 


\title{
Pagurus imafukui, a New Species of Deep-water Hermit Crab (Crustacea: Anomura: Paguridae), with Notes on its Larvas
}

\author{
Patsy A. McLaughim \\ Shannon Point Marine Center, Western Washington University, \\ 1900 Shannon Point Road, Anacortes, Washington 98221-4042, U.S.A. \\ and \\ Kootchi Konishi \\ National Research Institute of Aquaculture, Nansei, Mie 516-01, Japan
}

With Text-figures 1-4

\begin{abstract}
A new species of the hermit crab genus Pagurus was collected from depths of 126 and 300 meters off the Pacific coast of Japan. This is a strongly polymorphic species, which has been found only in shells of scaphopods (Order Dentalioida). Pagurus imafukui new species is described, illustrated and its morphological variations discussed. Aspects of early larval morphology of this species are also given.
\end{abstract}

Key words: Crustacea; Anomura; Paguridae; new species; larval development

\section{Introduction}

During the springs of 1991 and 1992, a number of hermit crabs were collected off Anorizaki, Mie Prefecture and Hamamatsu, Shizuoka Prefecture by fishermen for Takamitsu Ando of the Gamagori Aquarium. These specimens were passed on to Dr. Michio Imafuku, Kyoto University for identification and study. One species, a small inhabitant of Dentalium shells defied identification. Dr. Imafuku consulted with the authors who ascertained that it represented an undescribed taxon. In possessing a relatively straight abdomen, symmetrical or only slightly asymmetrical uropods and somewhat operculate right cheliped, and its veteracy for dwelling in tusk shells, this species resembles species of Pylopagurus A. Milne Edwards \& Bouvier, sensu stricto (cf. McLaughlin, 1981); however, the absence, in females, of paired first pleopods modified as gonopods, precludes referral of this species to Pylopagurus. In spite of certain distinctive characters, this species must be assigned to Pagurus, until such time as this admittedly heterogeneous genus (cf. Forest \& De Saint Laurent, 1968; McLaughlin, 1974) is thoroughly reviewed.

Despite the relative brevity of the prezoeal stage in decapod development, its occurrence has raised considerable interest and in some cases also controversy (see Gore, 1985 for review). In the genus Pagurus, only limited information on the occurrence of prezoeas is available. Detailed descriptions of three Japanese species were provided by Quintana \& Konishi (1986) and two European species by Hong

Publ. Seto Mar. Biol. Lab., 36(4), 211-222, 1994.

(Article 16) 
(1988). McLaughlin et al. (1992) noted the occurrence of prezoeas in Pagurus ochotensis Brandt, but did not describe their morphology. McLaughlin and Gore (1992) presumed that $P$. armatua Dana hatched as prezoeas, but could not confirm the event. The occurrence of a prezoeal stage in $P$. imafukui n. sp. has been documented. First zoeas also were obtained from a specimen whose eggs hatched in the laboratory of one of the authors (K.K.).

\section{Materials and Methods}

Specimens were collected by fishermen using trawling gear in April of 1991 and March of 1992, passed on to the Gamagori Aquarium, and then to Dr. Imafuku. One measurement, shield length (SL), as measured from the tip of the rostrum to the midpoint of the cervical groove provides an indication of adult animal size; carapace length (CL), as measured from the tip of the rostrum to the midpoint of the carapace provides zoeal size. The holotype and several paratypes have been deposited in the National Science Museum, Tokyo (NSMT). Additional paratypes have been deposited in the Osaka Museum of Natural History, Osaka (OMNH), the National Museum of Natural History, Smithsonian Institution (USNM), and the Swedish Natural History Museum, Stockholm (SNHM). Two prezoeas and three early zoeas I were obtained from one female $(\mathrm{SL}=1.4 \mathrm{~mm}$ ) collected at Anorizaki in 1991, and apparently preserved just as the eggs were hatching. From a female ( $\mathrm{SL}=1.9 \mathrm{~mm}$ ) collected off Hamamatsu, first stage zoeas, which hatched in the laboratory of one of the authors (K.K.) have provided material for a complete description of this stage.

Adults and prezoeas were stained with $1 \%$ chlorazol black in lactic acid and phenol (cf. Bidle \& McLaughlin, 1992) to elucidae character details. Most of the illustrations were drawn and edited using

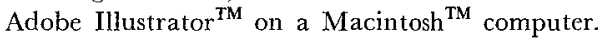

\section{Pagurus imafukui new species}

Figures 1-3.

Material examined

Holotype: male (SL=2.3 mm), off Hamamatsu, Shizuoka Prefecture, March 21, 1992, $300 \mathrm{~m}$, NSMT-Cr 11372.

Paratypes: 10 males, 6 females, 8 ovigerous females ( $\mathrm{SL}=1.4-2.4 \mathrm{~mm}$ ), off Hamamatsu, Shizuoka Prefecture, March 21, 1992, 300 m, NSMT-Cr 11377-79, 11382, 11385, OMNH AR 3827-35, SMNH 4610, USNM 265375; 13 males, 4 females, 7 ovigerous females (SL $=1.3-2.4 \mathrm{~mm}$ ), off Anorizaki, Mic Prefecture, April 3-11, 1991, 126 m, NSMT-Cr 11373-76, 11380-81, 11383-84, OMNH AR 3818-26, SNHM 4609, USNM 265374.

Description

Shield slightly (as in holotype and illustrated paratype) to considerably longer than broad; anterior margin between rostrum and lateral projections concave; 2anterolateral margins sloping; posterior margin roundly truncate; surface with few scattered tufts of setae, and occasionally short, rounded, longitudinal ridge anteriorly in midline. Rostrum broadly triangular, with weak to moderately strong terminal spine. Lateral projections obtusely triangular, with marginal spine.

Ocular peduncles short, approximately two-thirds length of shield 0.69 in holotype), often somewhat bulbous basally, corneae not dilated, dorsomesial surface with longitudinal row of widely-spaced tufts of long, stiff setae. Ocular acicles narrowly triangular, terminating subacutely and with very strong mesial marginal or submarginal spine; separated basally by one and one-half to almost twice basal width of 1 acicle. 


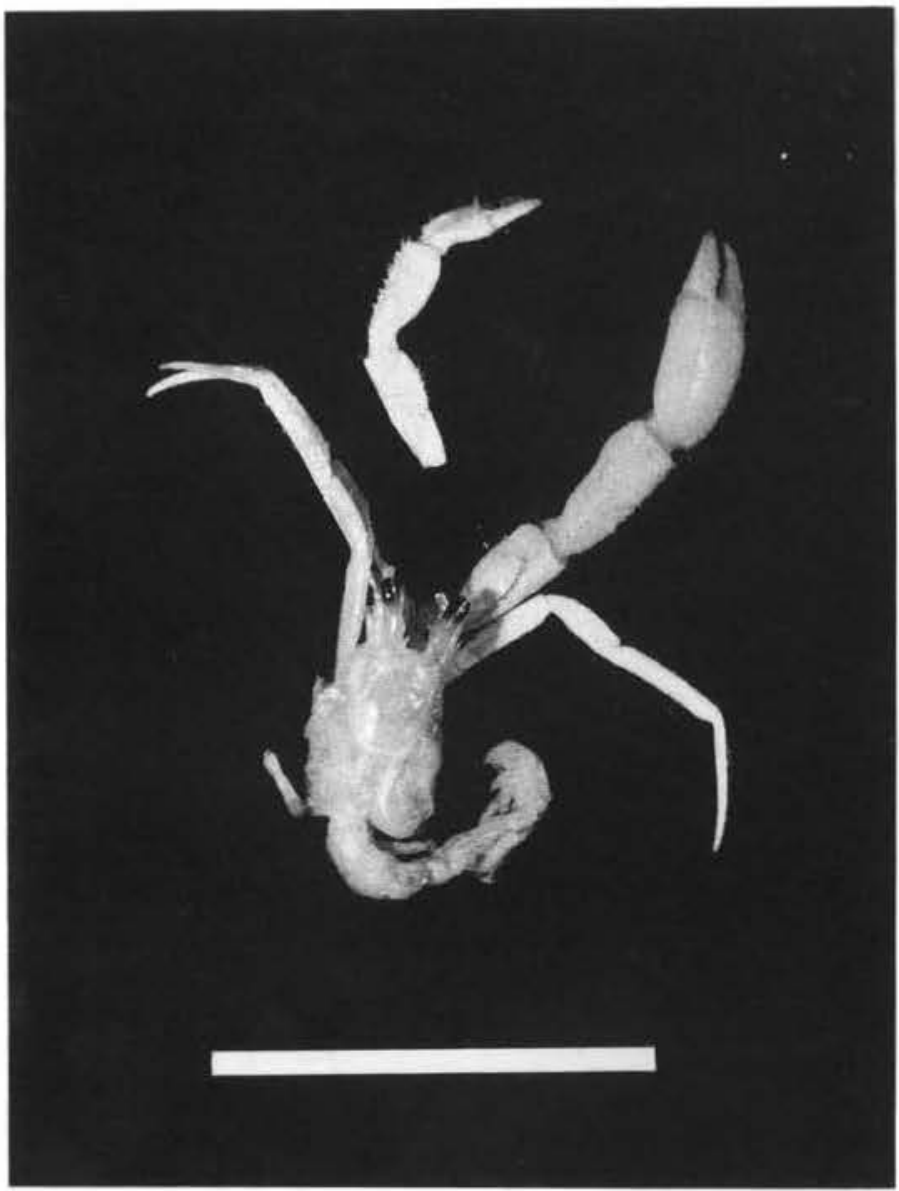

Fig. 1. Pagurus imafukui new species. Holotype (NSMT-Cr 11372) in dorsal view. Bar equals $10 \mathrm{~mm}$.

Antennular peduncles overreaching corneae by one-third to one-half length of ultimate segment. Ultimate segment with 1 very long, stiff seta at distal margin, reaching almost to tip of upper antennular flagellum and provided with paired long setules at least in distal half to two-thirds. Penultimate segment with few scattered short setae. Basal segment with small spine on lateral face.

Antennal peduncle overreaching ocular peduncle by one-fourth to one-half length of ultimate segment; supernumerary segment present. Fifth and fourth segments with few scattered setae. Third segment with small spine sometimes partially obscured by tuft of setae at ventrodistal angle. Second segment with dorsolateral distal angle very prominently produced, reaching to mid or distal portion of fourth segment and terminating in very strong simple or rarely bifid spine, usually with 1 accessory strong spine, occasionally 2 or 3 smaller spines on lateral margin; dorsomesial distal angle 


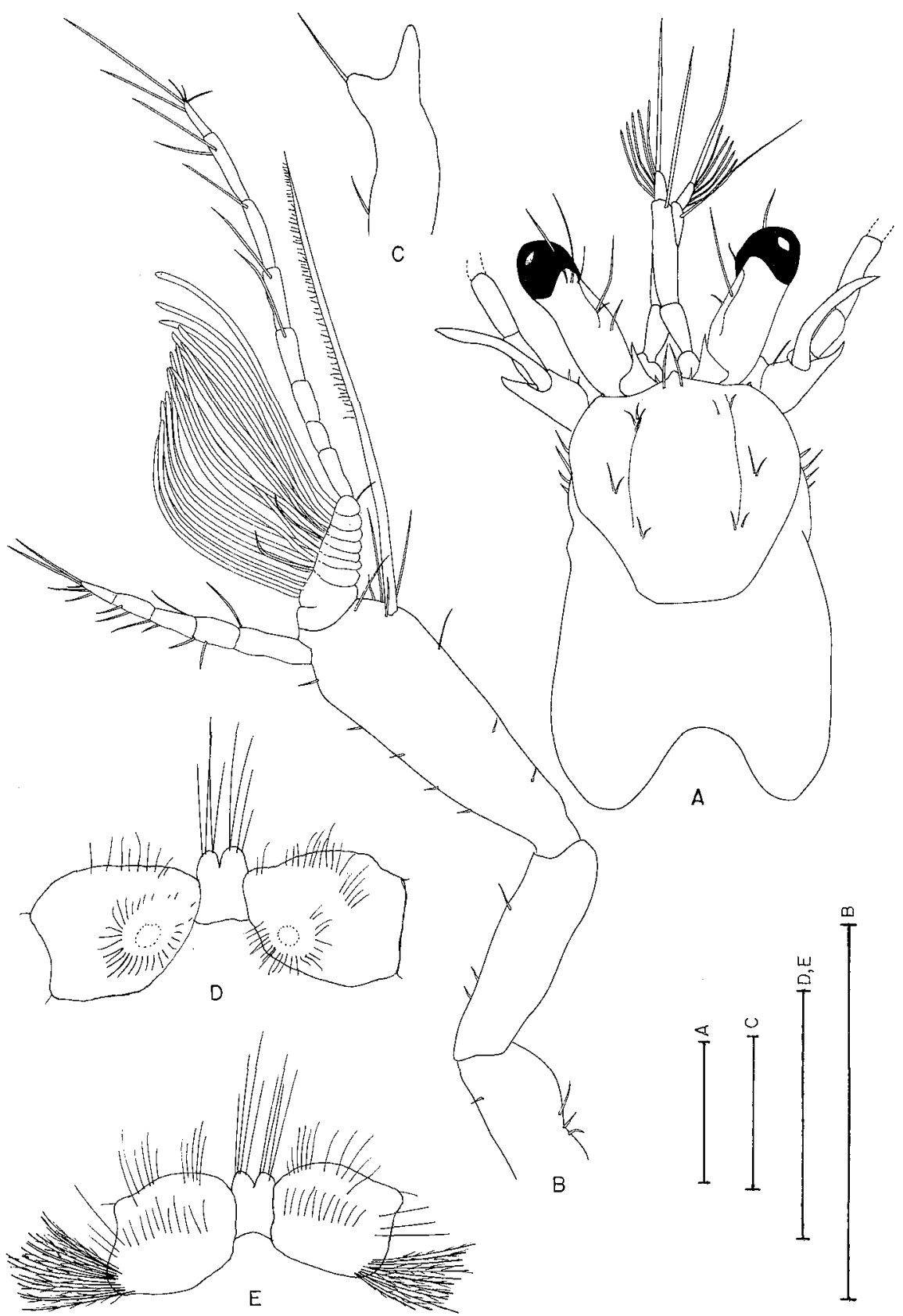

Fig. 2. Pagurus imafukui new species. A, cephalothorax and cephalic appendages (paratype ovigerous female, Hamamatsu); B, antennule (paratype male, Anorizaki); C, enodpod of maxillule (paratype female, Hamamatsu); D, ventral aspect of coxae and sternite of fifth pereopods (paratype male, Anorizaki); E, ventral aspect of coxae and sternite of fifth pereopods (paratype female, Hamamatsu). Scales equal $0.25 \mathrm{~mm}(\mathrm{C})$ and $1.0 \mathrm{~mm}$ (A, B, D, E). 
with very prominent, slender, acute spine. First segment with spine on lateral margin distally, ventral margin produced, unarmed or with 1 spine. Antennal acicle long, reaching to distal half of ultimat peduncular segment, arcuate, terminating in acute spine, mesial margin with row of tufts of setae. Antennal flagellum usually slightly shorter than right cheliped, each article with 1-3 short ( $\geq 1$ article length) and 1 or 2 very short setae.

Maxillule with I long bristle on internal endopodal lobe, external lobe moderately well developed, not recurved. Third maxilliped with teeth of crista dentate large proximally, decreasing in size and strength distally, 1 prominent accessory tooth; basis with 3 or 4 strong teeth; merus and carpus lacking dorsodistal spine. Sternite of third maxillipeds with small spine on either side of slightly concave midline.

Chelipeds grossly unequal. Right cheliped larger and morphologically variable: often subquadrate or subrectangular and semioperculate in small individuals, becoming longer and more slender (as in holotype) with increasing size. Dactyl one-half (as in holotype) to two-thirds length of palm; cutting edge with row of calcareous teeth, largest proximally, terminating in small corneous claw; dorsal surface concave or flattened, unarmed, but with scattered, moderately long setae; dorsomesial margin with row of small spines or tubercles, decreasing in size and becoming obsolete distally, and few moderately long setae. Palm three-fourths to approximately equaling (as in holotype) carpus in length; dorsomesial margin not distinctly delimited, rounded and armed with only few minute spinules or tubercles, or angular and armed with 2 or 3 irregular longitudinal rows of small spines, spinules or tubercles, frequently 1 prominent spine at dorsomesial proximal angle, dorsal surface convex and unarmed or generally flattened and with numerous small spines, spinules or tubercles sometimes forming irregular row, dorsolateral margin with row of small spines, usually obsolete in proximal third, but increasing in size distally and extending almost to tip of fixed finger; cutting edge of fixed finger with row of small calcareous teeth, terminating in very small corneous claw. All surfaces and margins with numerous moderately long setae. Carpus approximately as long as merus; dorsomesial margin with row of small to moderately strong spines; dorsolateral margin with 1 or 2 irregular rows of usually smaller spines proximally, sometimes becoming obsolete distally or more frequently shifting to dorsal surface distally, dorsodistal margin rarely with 1 or 2 small spines; ventrolateral margin often with 1-3 spines distally; all surfaces with numerous moderately long setae. Merus triangular; dorsal margin with short, transverse rows of short setae; ventrolateral margin with row of small spines, sometimes subacute and only in distal third, more often acute along entire margin; ventromesial margin with 4, rarely 3 or 5 , acute or blunt spines in proximal two-thirds; ventral surface and margins also with long setae. Ischium unarmed, but with few moderately long setae on ventral margin.

Left cheliped with dactyl exceeding length of palm by one-fourth to one-third own length; cutting edge with row of very fine corneous teeth, terminating in small corneous claw; dorsal, mesial and ventral surfaces unarmed but with scattered moderately long setae. Palm two-thirds to three-fourths length of carpus; triangular 


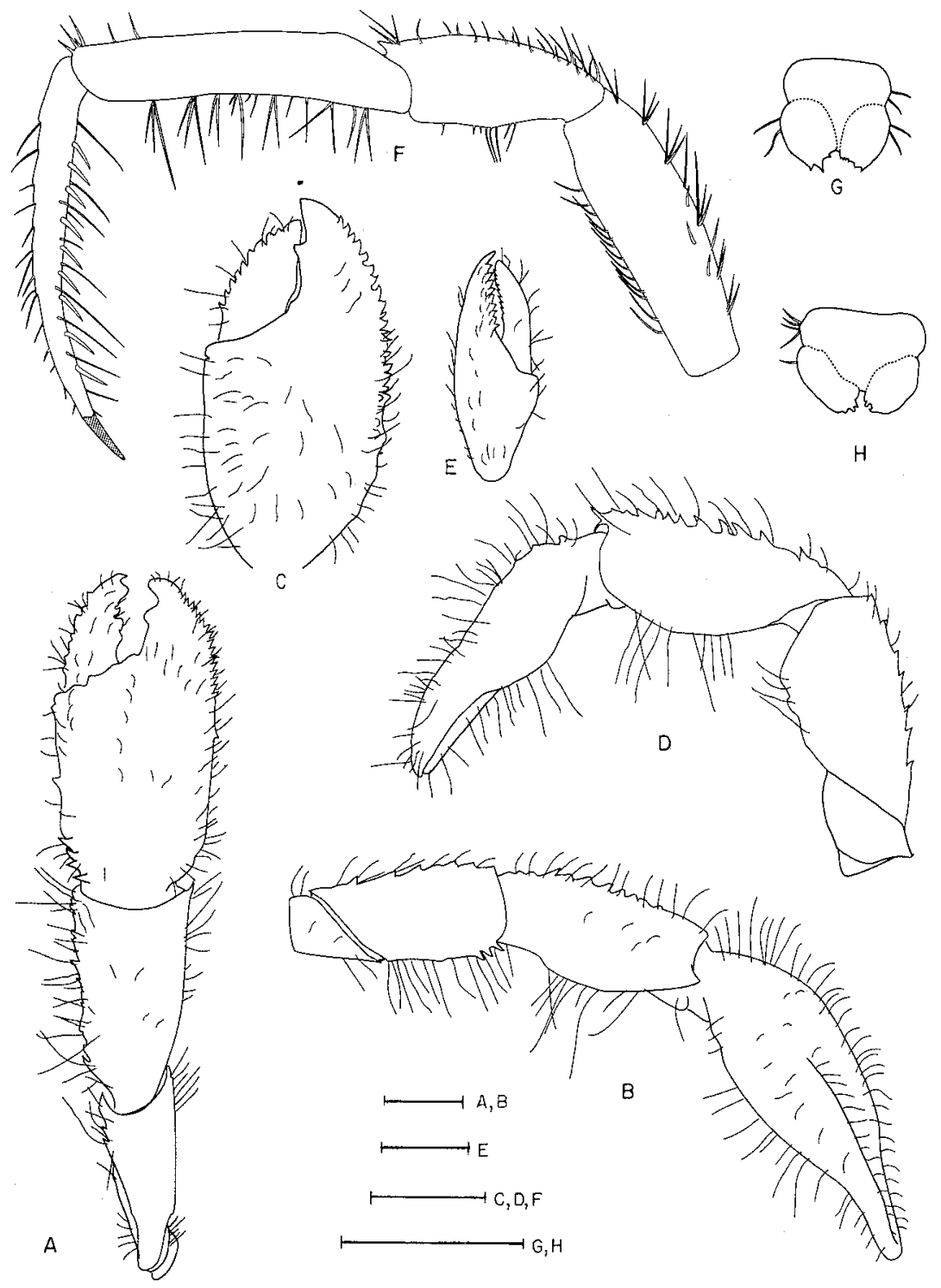

Fig. 3. Pagurus imafukui new species. A, B, G, right cheliped and telson (paratype male, Anorizaki), C, E, right and left chelae (paratype ovigerous female, Hamamatsu); $\mathrm{D}, \mathrm{F}$, left cheliped and 2nd left pereopod (paratype male, Anorizaki); H, telson (paratype ovigerous female, Anorizaki): A, dorsal view; B, lateral view, C, dorsal view; D, lateral view, $\mathrm{E}$, dorsal view; $\mathrm{F}$, lateral view; $\mathrm{G}$, dorsal view; $H$, dorsal view. Scales all equal $1.0 \mathrm{~mm}$. 
in cross-section, dorsal surface elevated in midline, sometimes forming distinct ridge or crest, and armed with 1 or 2 irregular rows of moderately small spines or tubercles, extending onto fixed finger proximally; dorsolateral surface strongly sloping ventrally, dorsolateral margin with row of small spines or spinules; dorsomesial surface also strongly sloped ventrally, dorsomesial margin unarmed; all surfaces and margins with scattered long setae. Carpus approximately as long as merus; dorsolateral margin with row of acute or subacute spines, dorsomesial margin with row of protuberances, tubercles or spines and tufts of long setae, 1-3 spines at dorsomesial distal angle; all surfaces with scatted long setae. Merus with short, transverse rows of setae on dorsal margin; ventromesial margin with incomplete or complete row of small protuberances, tubercles or spines; ventrolateral margin unarmed or with 1 or 2 spines distally; ventral surface and margins all with scattered long setae. Ischium with few scattered long setae.

Ambulatory legs similar from left to right (right third absent from holotype photograph, but not actually missing). Dactyls slightly longer than propodi; in dorsal view, straight or very slightly twised, in lateral view, almost straight or slightly curved in distal half; terminating in long, slender, corneous claws; dorsal margins each with row of long, relatively stiff setae and scattered shorter setae; lateral and mesial faces each with few tufts of setae; ventral surfaces each with 7-10 corneous spines, increasing in length distally. Propodi approximately equal to nearly one-third longer than carpi; with numerous long, stiff setae on dorsal surfaces, scattered setae on mesial and lateral faces and ventral surfaces; ventrodistal margins each usually with 1 or 2 corneous spinules. Carpi two-thirds to three-fourths length of meri; each usually armed with 1 spine at dorsodistal angle; second pereopods, and often also third, frequently with additional spinulose protuberance or small spine and tuft of setae on dorsal surface in proximal half, second occasionally with 2 widely-spaced spines in posterior two-thirds; both second and third pereopods with row of long, moderately stiff setae on dorsal surface, and 1 or 2 tufts on ventral surface. Meri each with row of long setae on dorsal and ventral sufaces. Ischia with few long setae on vetral margins. Dactyls of fourth perepods each with small preungual process at base of claw; propodal rasp formed of single row of corneous scales. All segments with tufts of long setae.

Sternite of third pereopods with semisubovate anterior lobe, unarmed but with several very long setae. Sternite of fifth pereopods developed anteriorly as two ovate, nearly approximate lobes. Females with paired gonopores; coxae of fifth pereopods each with cluster of dense, long setae on posterolateral margin; no paired pleopods; four unpaired, biramous pleopods, $\mathrm{pl}_{2}$ to $\mathrm{pl}_{4}$ with both rami well developed, $\mathrm{pl}_{5}$ with exopod moderately well developed, endopod reduced. Males with paired gonopores circumscribed posteriorly by row of moderately short setae; no sexual tubes or paired gonopods; three unpaired pleopods, $\mathrm{pl}_{3}$ and $\mathrm{pl}_{4}$ with exopods moderately well developed, endopods reduced, $\mathrm{p} 1_{5}$ with exopod moderately well developed, endopod rudimentary or vestigial.

Abdomen generally straight. Uropods usually symmetrical, occasionally slightly asymmetrical; exopods and endopods both with well developed rasps. Telson with 
transverse suture; posterior lobes usually symmetrical, separated by moderately well developed median cleft; terminal margins oblique or nearly perpendicular, armature varying from 2 or 3 small and 1 larger marginal spines and 1 very prominent spine at outer terminal angle to all spines markedly reduced or obsolete; lateral margins usually with narrow fused corneous plate, occasionally inconspicuous.

Color (based on notes of living animals made by Dr. Imafuku). Overall appearance of orange to reddish orange on transparent or white background. Carapace orange to reddish orange. Antennules and antennae light orange. Chelipeds with dactyl and palm white, carpus and merus orange. Ambulatory legs white with some orange bands: dactyls transparent or white and occasionally with light orange proximally; propodi with wide band medially; carpi orange, with white proximally and distally; meri with narrow band near distal end and wide band extending from middle to proximal end. Yolk of eggs dark chocolate.

Variation. Pagurus imafukui exhibits marked variation in the shape and armature of the right cheliped, but neither appears attributable to sexual dimorphism. Increased body size usually results in reduced width and increased length of the right chela in both sexes. These changes in the chela may be accompanied by either increased size and strength of spination or by marked reduction. As is indicated in the description, the telson also displays appreciable variation. When the terminal margins of the posterior lobes are oblique, the armature usually consists of 1-3 small spines close to the median cleft, 1 larger marginal spine and 1 very prominent spine at the terminal angle; occasionally only the 1 prominent marginal spine and 1 major spine at the terminal angle are present. In contrast, when the terminal margins are perpendicular, or nearly so, the marginal spines and/or terminal spines are appreciably reduced, obsolete, or completely absent.

Remarks. One male ( $\mathrm{SL}=1.3 \mathrm{~mm}$ ) from Hamamatsu was heavily parasitized by a rhizocephalan. Unlike all non-parasitized males examined, this specimen had the tufts of setae posteriorly on the coxae of the fifth pereopods that are characteristic of females of this species. However, a second similarly parasitized male ( $\mathrm{SL}=1.8$ $\mathrm{mm}$ ) from the same station did not exhibit this 'feminization'.

Etymology. This species is named for Dr. Michio Imafuku, Kyoto University, in recognition of his contributions to pagurid behavior and systematics, and in appreciation for having made specimens available to us.

Associated fauna. Also collected off Hamamatsu during 1992 were four additional deep-water species, i.e., Paguristes incomitatus Alcock, Sympagurus monstrosus (Alcock) (cf. Lemaitre, 1989), Catapagurus doederleini Doflein, and Catapagurus japonicus Yokoya.

\section{Larval morphology}

Egg size early in development 1.4-1.5 mm diameter; at hatching $1.8 \mathrm{~mm}$ diameter. Prezoeas covered with very thin cuticle. Antennule with 2 long, plumose, terminal processes and 1 shorter subterminal process. Antenna with 2 apical plumose processses on endopod; scaphocerite with 8 or 9 plumose processes and 1 strong terminal spine. No distinct setation observed on telson cuticle. 


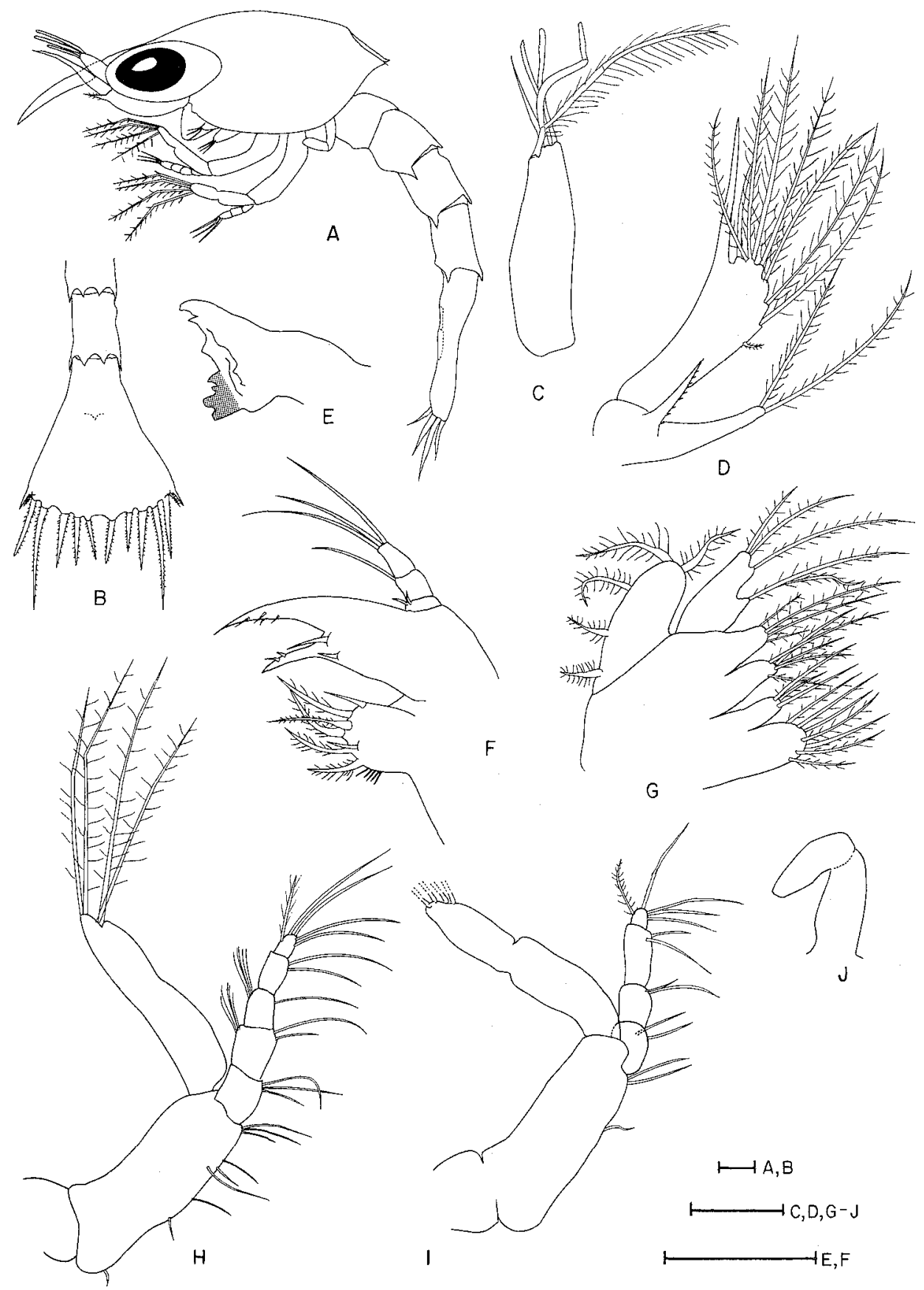

Fig. 4. Pagurus imafukui new species. A-J, first zoea (from female from Hamamatsu): A. whole animal (lateral view); B, posterior abdominal somites and telson (dorsal view); $\mathrm{C}$, antennule; D, antenna; E, mandible; F, maxillule; G, maxilla; $\mathrm{H}$, first maxilliped; I, second maxilliped; J, third maxilliped. Scales all equal $0.1 \mathrm{~mm}$. 
Description of First Zoea

Carapace (Fig. 4A): $\mathrm{CL}=1.08-1.13 \mathrm{~mm}$ (mean $1.11 \mathrm{~mm}$ ). Rostral spine curved ventrally between large sessile eyes; posterolateral carapace spines short.

Abdomen (Figs. 4A,B): Five well differentiated somites, second through fifth with pair of posterolateral spines apparent, strongest on fifth. Telson broadly triangular, with V-shaped median cleft; outermost process (1st) fused smooth small spine; anomuran hair (2nd process) clearly discernible, five inner processes (3-7) plumodenticulate, articulated. Anal spine present.

Antennule (Fig. 4G): Uniramous process with 3 aesthetascs, 1 naked seta, and 1 long subterminal plumose seta.

Antenna (Fig. 4D): Biramous; protopod with strong spine armed with spinules at base of endopodal junction. Endopod with 2 partially extruded terminal setae. Exopod (=scaphocerite) with 8 or 9 partially extruded setae and strong terminal spine; 1 minute plumose seta on inner margin.

Mandible (Fig. 4E): Molar and incisor processes well developed.

Maxillule (Fig. 4F): Coxal endite with 5 plumodenticulate and 2 naked setae. Basial endite with 2 strong spines each armed with 1 or 2 prominent denticles, 2 short naked setae subterminally. Endopod 3-segmented, with setation proceeding distally $2,1,3$.

Maxilla (Fig. 4G): Coxal and basial endites bilobed, with $7+3$ and $5+4$ (proximal to distal) setae, respectively. Endopod unsegmented, with $2+3$ setae. Scaphognathite with 5 marginal setulate plumose setae.

Maxilliped 1 (Fig. 4H): No coxal setae. Basis with 1,2,3,3 (proximal to distal) setae. Endopod 5-segmented, setation proximal to distal 3,2,1,2,4+I (I denoting dorsolateral plumose seta). Exopod with 4 long natatory plumose setae.

Maxilliped 2 (Fig. 4I): No coxal setae. Basis with 1,2 setae, Endopod 4-segmented, with 2,2,2,4+I setae. Exopod with 4 plumose, natatory setae.

Maxilliped 3 (Fig. 4J): Uniramous, rudimentary.

\section{Discussion}

Adults of $P$. imafukui, while sharing general morphological traits with other Japanese species of Pagurus, cannot be easily related to any particular taxon. In its apparent preference for the tusk shell microhabitat (housing), Pagurus imafukui resembles Pylopagurus serpulophilus Miyake, a species now considered by McLaughlin and Gunn (1992) to be synonymous with Australeremus triserratus (Ortmann). However, not only the absence of paired female gonopods, but the general morphology of $P$. imafukui distinguishes it from $A$. triserratus and other habitat specialists. Particularly distinctive is the very elongate seta on the ultimate antennular segment. The series of paired setules over the distal half or two-thirds of this seta (Fig. 2B), suggests a possibly unique sensory role for the antennules in this species.

Sexual dimorphism is common in hermit crabs, and most frequently is reflected by changes in the major cheliped (e.g., Asakura, 1987; Blackstone, 1987). Chela 
polymorphism occurs in $P$. imafukui, but is not sexually influenced. With increasing body size, the right chela changes from a moderately short and broad, semi-operculate configuration to a much longer and more slender, non-operculate shape in both sexes.

Sexual dimorphism, however, is apparent in the setation of the coxae of the fifth pereopods. In females, the posterior margins of these segments of the fifth pereopods (Fig. 2E) are provided with tufts of long setae. These setae are totally lacking in normal males (Fig. 2D) of any size. The function these setae may play is unknown.

Because major morphological changes frequently occur as larvas progress from one zoeal stage to the next, characters of first stage zoeas can provide only limited information regarding relationships with other taxa. Of the 45 species of Pagurus for which some data on first stage zoeas have been documented, $P$. imafukui agrees in all available characters only with $P$. kulkarnii Sankolli, as described by Shenoy (1967) and Tirmizi \& Siddiqui (1980). However, the major differences between adults of the two species suggest that these similarities do not persist through subsequent zoeal stages.

\section{Acknowledgements}

We are most grateful to Dr. Michio Imafuku for bringing this species to our attention, providing much corollary information, and granting us permission to describe it. We also acknowledge, with thanks, the contribution of Takamitsu Ando. Cordial thanks are also due to Ms. Maya Kurihara for the preparation of the drawings. This is a scientific contribution from the Shannon Point Marine Center, Western Washington University.

\section{References}

Asakura, A. 1987. Polymorphism in the chelae of Diogenes nitidimanus Terao (Decapoda: Diogenidae). Res. Crust., 16: 30-37.

Bidle, K.D. \& P.A. McLaughlin, 1992. Development in the hermit crab Pagurus caurinus Hart (Decapoda: Anomura: Paguridae) reared in the laboratory. Part I. Zoeal and megalopal stages. J. Crust. Biol., 12: 224-238.

Blackstone, N.W. 1987. Specific growth rates of parts in a hermit crab: A reductionist approach to the study of allometry. J. Zool. London (A), 211: 531-545.

Forest, J. \& M. de Saint Laurent. 1968. Résultats scientifiques des campagnes de la 'Calypso', Part VII. Campagne de la Calypso au large des côtes Atlantiques de l’Amérique du Sud (1961-1962). 6 Crustacés Décapodes: Pagurides. Ann. Inst. Ocćanogr., 45: 45-169.

Gore, R.H. 1985. Molting and growth in decapod larvae. In: A.M. Wenner (ed.), Crustacean growth: Larval growth. Crustacean issues, 2; 1-65. A.A. Balkema, Rotterdam.

Hong, S.Y. 1988. The prezoeal stage in various decapod crustaceans. J. nat. Hist., 22: 1041-1075.

Lemaitre, R. 1989. Revision of the genus Parapagurus (Anomura: Paguroidea: Parapaguridae), including redescriptions of the western Atlantic species. Zool. Verhandel., 253: 1-106.

McLaughlin, P.A. 1974. The hermit crabs (Crustacea Decapoda, Paguridea) of northwestern North America. Zool. Verhandel., 130: 1-396.

- 1981. Revision of Pylopagurus and Tomopagurus (Crustacea: Decapoda: Paguridae), with the descriptions of new genera and species: Part I. Ten new genera of the Paguridae and a redescription of Tomopagurus A. Milne Edwards and Bouvier. Bull. mar. Sci, 31: 1-30.

- \& R.H. Gore. 1992. Studies on the provenzanoi and other pagurid groups: VII. The zoeal and megalopal stages of Pagurus armatus (Dana) (Decapoda: Anomura: Paguridae) reared in the laboratory. J. Crust. Biol,, 12: 448-463.

\& S.W. Gunn. 1992. Revision of Pylopagurus and Tomopagurus (Grustacea: Decapoda: Paguridae), 
with the descriptions of new genera and species: Part IV. Lophopagurus McLaughlin and Australeremus McLaughlin. Mem: Mus. Victoria, 53: 43-99.

- J.A. Crain, \& R.H. Gore. 1992. Studies on the provenzanoi and other pagurid groups: VI. Larval and early juvenile stages of Pagurus ochotensis Brandt from the eastern North Pacific reared under laboratory conditions. J. nat. Hist., 26: 507-531.

Quintana, R. \& K. Konishi. 1986. On the prezoeal stage: observations on three Pagurus species (Decapoda, Anomura). J. nat. Hist., 20: 837-844.

Shenoy, S. 1967. Studies on larval development in Anomura (Crustacea, Decapoda)--II. In: Proceedings of the Symposium on Crustacea, Mar. Biol. Ass. India, 2: 777-804.

Tirmizi, N.M. \& F.A. Siddiqui. 1980. Notes on the laboratory reared larvae of Pagurus kulkarnii Sankolli (Dccapoda, Paguridac). Crustaceana, 38(2): 155-168. 